\title{
Erektil disfonksiyonlu diabetes mellitus olgularında penil Doppler ultrasonografi bulguları
}

\author{
Penile Doppler ultrasound findings in diabetic patients with erectile dysfunction \\ Namık Kemal Altınbaş ${ }^{1} \quad$ Nurullah Hamidi $^{2} \quad$ Cemil Yağcı $^{1}$ \\ ${ }^{1}$ Ankara Üniversitesi Tıp Fakültesi, Radyoloji Anabilim Dalı, Ankara, Türkiye \\ ${ }^{2}$ Ankara Üniversitesi Tıp Fakültesi, Üroloji Anabilim Dalı, Ankara, Türkiye
}

\section{Öz}

Amaç: Penil Doppler ultrasonografi (US) incelemesi istenen erektil disfonksiyon şikayeti bulunan diabetes mellitus tanılı hastalarda US bulgularının erektil fonksiyon skorlama testi ile karşılaştırılarak değerlendirilmesi amaçlandı.

Gereç ve Yöntem: Penil Doppler US incelemesi yapılan 27 hasta prospektif yürütülen bu çalışmaya dahil edildi. Hastalara US ünitesinde, penil kavernöz cisme papaverin enjeksiyonunu takiben Doppler US yapılarak penil kan akımı değerlendirildi. Pik sistolik akım hızı, diyastol sonu hız kaydedilerek Doppler US tanısı belirlendi. Ereksiyon düzeyi, ereksiyon sertlik derecelendirme skalasına göre 4 puan üzerinden değerlendirildi. Erektil fonksiyon için IIEF-5 (erektil fonksiyon uluslararası indeksi) anketi ile skorlama yapıldı ve SHIM (erkekler için seksüel sağlık envanteri) seviyesi belirlendi. Elde edilen Doppler US tanıları ile SHIM seviyeleri karşılaştırıldı.

Bulgular: Çalışma dahilinde 27 hasta mevcuttu. Hastaların yaş ortalaması 55.74 \pm 9.02 (aralık 39-70) idi. Hastaların 21 'inde (\%78) anormal penil Doppler US bulguları elde edildi. Hastalar Doppler US bulgularına göre normal ( $n=6)$, arteriyel yetmezlik için sınırda $(n=2)$, arteriyel yetmezlik $(n=5)$ ve venöz yetmezlik $(n=14)$ olarak sınıflandırıldı. Penil Doppler incelemesine bağlı olarak hiçbir hastada komplikasyon gelişmedi. Ereksiyon sertliği iki hasta hariç diğerlerinde tam düzeyde değildi. En düşük ereksiyon sertlikleri ve IIEF-5 skorları arteriyel problem durumunda gözlendi.

Sonuç: Erektil disfonksiyon şikayeti bulunan diabetes mellitus tanılı hastalarda vasküler problem oranı yüksektir ve çalışmamızda özellikle venöz yetmezlik daha sık olarak gözlenmiştir.

Anahtar Sözcükler: Diabetes mellitus, erektil disfonksiyon, IIEF-5 anketi, penil Doppler US.

\section{Abstract}

Aim: To evaluate the correlation between penile Doppler ultrasound (US) findings and erectile function scoring test in patients with diabetes mellitus requested penile Doppler US examination and suffering from erectile dysfunction.

Materials and Methods: Twenty-seven patients who underwent penile Doppler US were recruited to this prospective study. Penile blood flow following intracavernosal papaverine injection using Doppler US was evaluated in the ultrasound unit. The peak systolic velocity and end-diastolic velocity were recorded and the diagnosis according to Doppler US was determined. Erection score according to Erection Hardness Grading Scale was evaluated, which ranked the scores from 1 to 4 . A scoring for erectile function was performed with the International Index of Erectile Function (IIEF-5), and the Sexual Health Inventory for Men (SHIM) was defined. Doppler US findings were compared with SHIM scales.

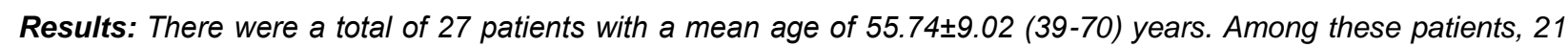
(78\%) had abnormal penile Doppler US findings. According to Doppler US findings, patients were classified as normal $(n=6)$, borderline for arterial insufficiency $(n=2)$, arterial insufficiency $(n=5)$, and venous insufficiency $(n=14)$. No complications were detected in any of the patients due to penile Doppler US evaluation. Erection was not completely enough except in 2 patients. The lowest erection hardness and the lowest IIEF-5 scores were detected in the patients with arterial problems.

Conclusion: The rate of vascular problems in diabetic men with erectile dysfunction is high and venous insufficiency was found to be more often in our study.

Keywords: Diabetes mellitus, erectile dysfunction, IIEF-5 questionnaire, penile Doppler US.

\footnotetext{
Yazışma Adresi: Namık Kemal Altınbaş

Ankara Üniversitesi Tıp Fakültesi, Radyoloji Anabilim Dalı,

Ankara, Türkiye

Makalenin Geliş Tarihi: 24.10.2016 Kabul Tarihi: 11.01.2017
} 


\section{Giriş}

Ereksiyon, gerçek anlamda en azından bir duyusalmotor-sinir-hormonal-vasküler-psikososyal-kültürel ve kişilerarası bir olay olarak tanımlanmıştır (1). Erektil fonksiyonun bozulması altta yatan hipertansiyon, kardiyovasküler hastalık, periferik damar hastalığı ve diğer nörolojik ve endokrinolojik bozuklara işaret ediyor olabilir (2). Diabetes mellitus (DM) da erektil disfonksiyona (ED) neden olabilen önemli bir sağlık sorunudur. Vasküler ve/veya nörojenik tutulum ya da diğer etkiler ile kısa ya da uzun dönemde uç organ hasarlarına neden olabilmekte olup, gelişebilen ED da bu hastaların yaşam konforunu olumsuz yönde etkileyen önemli sorunlardan birisidir.

Erektil disfonksiyon olasılığı, diyabetik erkeklerde olmayanlara kıyasla 2-4 kat daha fazladır. Diyabetik hastalarda ED, diyabetik olmayan erkeklerden 10-15 yıl önce ortaya çıkmaktadır $(3,4)$. Diyabetik erkeklerde ED un daha ciddi olduğu ve daha kötü yaşam kalitesi ile ilişkili olduğu gösterilmiştir (5). Medikal tedaviye cevap da diyabetik olmayan hastalara kıyasla daha düşüktür (6). Diyabetik erkeklerde ED gelişim mekanizması olarak kavernöz arterlerde endoteliyal hasar, mikroanjiyopati (7) ve otonom nöropati (8) gibi nedenler tanımlanmıştır (9).

Renkli ve spektral penil Doppler US, ED'li hastaların değerlendirilmesinin önemli bir parçasıdır. Fonksiyonel anatominin bazal değerlendirmesini ve vazoaktif medikasyona cevaptaki dinamik değişikliklerin gerçek zamanlı ölçümünü sağlar (10). Penil Doppler US, ED araştırmasında kavernozal arter akım dinamiklerinin ölçümünü sağlar. İlk uygulandığı 1985 yılından bu yana tanısal amaçlı olarak kullanılmaktadır (11).

IIEF (erektil fonksiyon uluslararası indeksi) anketi ile skorlama, seksüel olarak aktif erkeklerde erektil disfonksiyon taraması için kullanılmaktadır (12). Bu anketin farklı toplumlar için çeşitli dillere çevrilmiş uzun (IIEF-15) ve kısa (IIEF-5) versiyonları mevcuttur (1214). IIEF, klinik çalışma ortamında, katılımcıların seksüel fonksiyonlarını değerlendirmek için güvenilir ve geçerli bir araç olarak kullanılmaktadır (14-15).

Bu çalışmada ED şikayeti bulunan, DM tanılı erkek hasta grubunda elde edilen Doppler US bulguları ile SHIM seviyelerinin karşılaştırılarak sunulması amaçlandı.

\section{Gereç ve Yöntem}

Hasta seçimi

Erektil disfonksiyonu bulunan ve penil Doppler US incelemesi için üroloji tarafından hastanemiz US ünitesine Nisan 2016 ile Eylül 2016 tarihleri arasında yönlendirilen hastalardan DM tanılı 27 hasta çalışmaya dahil edildi. Hastalar işlem ve çalışma hakkında bilgilendirildi. Hastalardan işlem için onam formu ve çalışma için aydınlatıımış gönüllü olur formu onayları alındı. Çalışmamız için kurumumuzdan etik kurul onayı alındı.

\section{Penil Doppler ultrasonografi}

Ultrasonografi incelemeleri 9L-D lineer prob ile donanımlı Logiq S7 Expert (GE Healthcare, Milwaukee, WI) US cihazı kullanılarak tüm hastalar için deneyimli tek bir radyolog tarafından gerçekleştirildi. Ultrasonografi ünitesindeki bir odada steril şartlar altında ve US kılavuzluğunda tek penil kavernöz cisme insülin iğnesi ile $2 \mathrm{ml}$ (60 mg) papaverin enjeksiyonu sonrası penil gri-skala US ve kavernöz arterlerden radiks düzeyine yakın proksimal alanlardan 30-60 derece örneklem aralığı gözetilerek uygun açıda penil renkli ve spektral Doppler US incelemeleri yapıldı. Gri skala US bulguları ve spektral Doppler bulguları [pik sistolik akım hızı (PSV), diyastol sonu hız (EDV)] kaydedildi. Rutin penil gri skala US işlemi sırasında transduser, ventral ve dorsal yüze transvers ve longitudinal yerleştirilerek kavernöz cisimler ve spongiöz cisim vizualize edildi. Proksimal, orta ve distal kesimler değerlendirildi. Olası plak yapıları, intrakavernozal lezyonlar ve üretral patolojiler ile dorsal penil damar anomalileri tarandı. İşlem 20. dakikada alınan spektral Doppler ölçümlerinin ardından sonlandırıldı. Hastalar işlem sonrası gelişebilecek priapizm gibi komplikasyonlara karşı bilgilendirilerek ilgili üroloji doktoruna yönlendirildi.

İlk 10 dakikada PSV düzeyine bakılarak arteriyel yeterlilik değerlendirildi. PSV değeri $30 \mathrm{~cm} / \mathrm{sn}$ 'nin üzerinde olduğunda arteriyel yeterliliğin bulunduğu, 25$30 \mathrm{~cm} / \mathrm{sn}$ arasında çıktığında arteriyel yetmezlik için sınırda olduğu kabul edildi. 10-20. dakikalar arasında EDV düzeyi göz önüne alınarak venöz yeterlilik değerlendirildi. İnceleme sürecinde bazal hattın altında EDV değerleri elde edildiğinde ya da 20. dakikada EDV değeri $5 \mathrm{~cm} / \mathrm{sn}$ 'nin altına düştüğünde venöz yeterliliğin bulunduğu kabul edildi. 20. dakika sonrası EDV değeri $5 \mathrm{~cm} / \mathrm{sn}$ 'nin üzerinde olan hastalar venöz yetmezlik olarak değerlendirildi $(11,16,17)$.

Ayrıca penil Doppler US sonrası 20. dakikadaki penil ereksiyon durumu kaydedildi. Ereksiyon düzeyi ereksiyon sertlik derecelendirme skalasına (Erection Hardness Grading Scale - EHGS) göre yapıldı. Penil boyut artışı var ancak sertlik yok ise grade 1, sertleşme var ancak penetrasyon için yeterli değilse grade 2, penetrasyon için yeterli sertleşme var ancak tam sert değilse grade 3 ve tam sertleşme var ve tümüyle rijit ise grade 4 olarak değerlendirildi $(6,18)$.

\section{IIEF-5 ve SHIM}

Üroloji doktoru tarafından, hastalarda erektil fonksiyonun değerlendirilmesi için IIEF-5 (erektil 
fonksiyon uluslararası indeksi) anketi ile skorlama yapıldı ve SHIM (erkekler için seksüel sağlık envanteri) seviyeleri belirlendi. Hastalar son 6 aydaki durumları için IIEF-5 anketi ile ereksiyon güven düzeyi, ereksiyon sertliği, ereksiyon idame sıklığı, ereksiyon idame gücü ve memnuniyet düzeyi olmak üzere 5 konuda sorgulandı. Her başlık, düşük puan kötü seksüel fonksiyonu temsil etmek üzere 1 'den 5 'e kadar puanlandı. Böylece IIEF-5 skoru, düşük skorlar artmış erektil disfonksiyonu göstermek üzere, 5 ile 25 arasında değişim gösterdi. IIEF-5 skoru 5-7 arasında olanlar ciddi ED, 8-11 arası olanlar orta ED, 12-16 arası olanlar hafif-orta ED, 17-21 arası olanlar hafif ED ve 22-25 arası olanlar ED yokluğu olarak değerlendirildi.

\section{Istatistiksel analiz}

İstatistiksel değerlendirme amacı ile hasta yaşını içeren temel veriler ile ereksiyon sertlik düzeyi, PSV ve EDV'yi içeren penil Doppler US bulguları ve elde olunan Doppler US tanıSı, IIEF-5 skoru ile SHIM seviyesi kullanıldı. Tanımlayıcı istatistik verileri oluşturuldu. İstatistiksel analizler Excel (Version 14.6.8, Microsoft Corporation, Redmond, WA, USA) ve SPSS (Version 20, IBM Corporation, Armonk, NY, USA) yazılımı ile değerlendirildi. SPSS yazılımı kullanılarak Doppler tanısına göre grup dağılımı normal olmayan bağımsız gruplar arasındaki ortancalar Kruskal-Wallis testi ile karşılaştırılarak değerlendirildi.

\section{Bulgular}

Çalışma dahilinde 27 diyabetik erkek hasta mevcuttu. Hastaların yaş ortalaması 55.74 \pm 9.02 yıl (aralık 39-70) idi. Hastaların glikozile hemoglobin ( $\mathrm{HbA} 1 \mathrm{c})$ ortalama düzeyleri \%9.75 \pm 2.15 (aralık 5.3-15.4) idi (Laboratuvar normal referans aralığı \% 4-6.5).

Hastaların 21'inde (\%78) anormal penil Doppler US bulguları elde edildi. Hastalar Doppler US bulgularına göre normal $(n=6)$, arteriyel yetmezlik için sınırda $(n=2)$, arteriyel yetmezlik $(n=5)$ ve venöz yetmezlik $(n=14)$ olarak sınıflandırıldı (Şekil-1). Her bir grup için ereksiyon dereceleri, IIEF-5 skorları ve SHIM seviyeleri ile ortalama PSV $(\mathrm{cm} / \mathrm{s})$ ve EDV $(\mathrm{cm} / \mathrm{s})$ değerleri Tablo1 de verildi.

Hiçbir hastada penil Doppler US işlemine bağlı komplikasyon gelişmedi. Gri-skala ile yapılan değerlendirmede bir hastada peyroni plağı saptandı. Hasta grubunda DM tanısına ek olarak hipertansiyon, hiperlipidemi, koroner ve periferik arter hastalıkları, kardiyak ritim bozukluğu, son dönem böbrek yetmezliği görülen diğer problemler arasındaydı.

Hastalar, fosfodiesteraz tip 5 (PDE5) enzim inhibitörlerine verdikleri yanıtlara göre yeterli cevap $(n=7)$, kısmi cevap $(n=3)$, cevapsızlık $(n=14)$ ve ilacı kullanamama $(n=3)$ (kardiyak ritim bozukluğu gibi medikal nedenlerden dolayı) şeklinde dört grupta incelendi. Doppler US bulgularına göre elde edilen her grupta her cevaptan mevcuttu. Örneğin venöz yetmezlik grubundaki 14 hastanın 9'unda cevapsızlık, birinde kısmi, üçünde yeterli cevap ve birinde de ilacı kullanamama durumu kaydedildi.

Ereksiyon sertlik seviyesi iki hastada tam düzeyde saptanmış olup bu hastalar Doppler bulgularına göre normal, IIEF-5 skorlarına göre ise biri 16 (hafif-orta ED) diğeri 19 (hafif ED) skoruna sahip idi. Diğer hastalarda ereksiyon tam düzeyde değildi. Ereksiyon sertliği Doppler bulgularına göre venöz yetmezlikli hastalarda çoğunlukla grade $3(12 / 14)$, arteriyel problemi olan hastalarda çoğunlukla grade 1 ve 2 düzeyinde saptandı. En düşük ereksiyon sertlikleri ve IIEF-5 skorları arteriyel problem durumunda gözlendi (Tablo1).

IIEF-5 skoru ile Doppler US bulguları karşılaştırıldığında en düşük IIEF-5 skorlarının arteriyel yetmezlik saptanan hastalarda kaydedildiği görüldü (Tablo-1).

Doppler tanısına göre oluşan 4 bağımsız grup (normal, arteriyel yetmezlik için sınırda, arteriyel yetmezlik ve venöz yetmezlik) arasındaki hasta yaşı, ereksiyon düzeyi, IIEF-5 skoru, SHIM, Vmax ve Ved değerleri arasında yapılan karşılaştırmaya göre yaş hariç diğer değerlerde gruplar arasında anlamlı düzeyde fark olduğu görüldü (Tablo-2).

Biri Doppler bulgusuna göre arteriyel yetmezlik, diğeri venöz yetmezlik tanısı alan iki hastaya penil protez uygulandı. Hastalara tek parçalı penil protez implantasyonu gerçekleştirildi. Bir hasta implantasyon sonrası gelişen yara yeri enfeksiyonu nedeni ile hospitalize edilerek medikal tedavi aldı. 


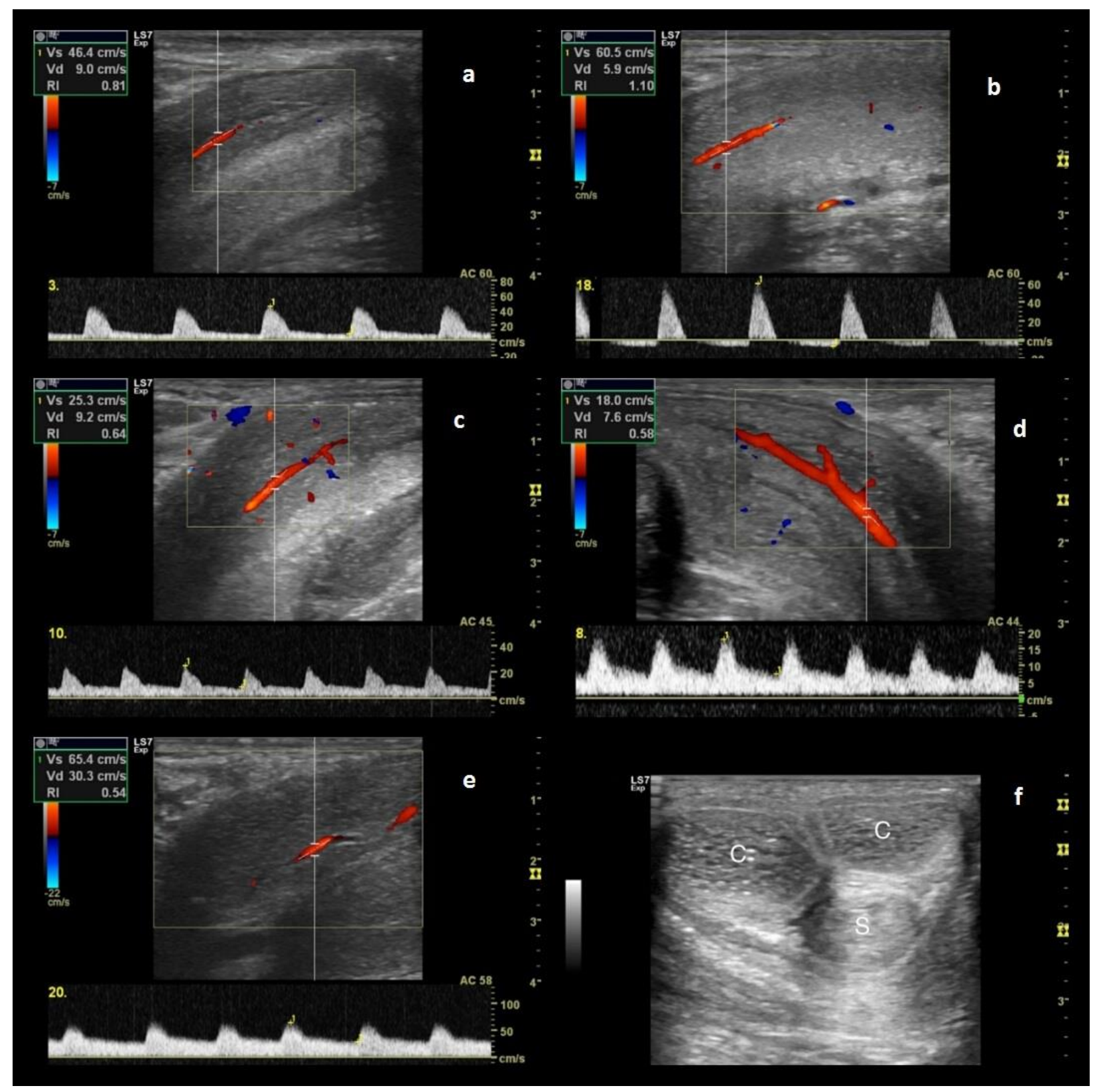

Şekil-1. Üçüncü dakikada PSV $46.4 \mathrm{~cm} / \mathrm{sn}$, 18. dakikada EDV $-5.9 \mathrm{~cm} / \mathrm{sn}$ ölçülen hastada normal PDUS bulguları mevcuttur. 56 yaşındaki bu hastanın IIEF-5 skoru 16, SHIM seviyesi hafif-orta ED, ereksiyon sertliği grade 4 düzeyinde olup DM'ye hiperlipidemi eşlik etmektedir (a,b). Onuncu dakikada PSV $25.3 \mathrm{~cm} / \mathrm{sn}$ ölçülen hastada arteriyel yetmezlik için sınırda PDUS bulguları mevcuttur. 64 yaşındaki bu hastanın IIEF-5 skoru 7, SHIM seviyesi ciddi ED, ereksiyon sertliği grade 1 düzeyinde olup DM'a prostatektomi öyküsü eşlik etmektedir (c). Sekizinci dakikada PSV $18 \mathrm{~cm} / \mathrm{sn}$ ölçülen hastada arteriel yetmezlik ile uyumlu PDUS bulguları mevcuttur. 56 yaşındaki bu hastanın IIEF-5 skoru 7, SHIM seviyesi ciddi ED, ereksiyon sertliği grade 1 düzeyinde olup DM'a hipertansiyon ve retinopati eşlik etmektedir (d). Yirminci dakikada EDV 30.3 $\mathrm{cm} / \mathrm{sn}$ ölçülen hastada venöz yetmezlik ile uyumlu PDUS bulguları mevcuttur. 69 yaşındaki bu hastanın IIEF-5 skoru 16, SHIM seviyesi hafif-orta ED, ereksiyon sertliği grade 3 düzeyinde olup yeni tanı almış olan DM'ye hipertansiyon ve TUR ameliyatlı BPH eşlik etmektedir. Penil spongiöz cisim (S) ödemi de inceleme esnasında not edilmiştir (e,f).

PSV: Pik sistolik akım hızı, EDV: Diyastol sonu hız, PDUS: Penil Doppler ultrasonografi, IIEF: Erektil Fonksiyon Uluslararası İndeksi (International Index of Erectile Function), ED: Erektil disfonksiyon, SHIM: Erkekler için Seksüel Sağlık Envanteri (Sexual Health Inventory for Men), TUR: Transüretral rezeksiyon, BPH: Benign prostat hipertrofisi, C: Kavernöz cisim, S: Spongiöz cisim. 
Tablo-1. PDUS Tanısına Göre Her Bir Grup İçin Ereksiyon Dereceleri, IIEF-5 Skorları ve SHIM Seviyeleri İle Ortalama PSV (cm/s) ve $\operatorname{EDV}(\mathrm{cm} / \mathrm{s})$ Değerleri.

\begin{tabular}{|c|c|c|c|c|c|c|c|c|c|c|c|c|c|}
\hline & \multicolumn{4}{|c|}{$\begin{array}{c}\text { Ereksiyon } \\
\text { Derecesi (1-4) }\end{array}$} & \multirow[t]{2}{*}{$\begin{array}{l}\text { IIEF-5 Skoru } \\
\text { (ortalama } \pm S D \text { ) }\end{array}$} & \multicolumn{5}{|c|}{ SHIM } & \multirow[t]{2}{*}{$\begin{array}{c}\text { PSV (cm/s) } \\
\text { (ortalama } \pm S D)\end{array}$} & \multirow[t]{2}{*}{$\begin{array}{l}\text { EDV }(\mathrm{cm} / \mathbf{s}) \\
\text { (ortalama } \pm S D \text { ) }\end{array}$} \\
\hline & & 1 & 2 & 3 & 4 & & 1 & 2 & 3 & 4 & 5 & & \\
\hline \multirow{4}{*}{ 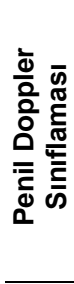 } & Normal $(\mathrm{n}=6)$ & 1 & 1 & 2 & 2 & $18.5 \pm 2.07$ & & & 1 & 4 & 1 & $52.75 \pm 10.76$ & $-3.28 \pm 5.9$ \\
\hline & $\begin{array}{c}\text { Arteriyel } \\
\text { yetmezlik için } \\
\text { borderline }(n=2)\end{array}$ & 1 & 1 & & & $10 \pm 4.24$ & 1 & & 1 & & & $28.6 \pm 1.98$ & $6.3 \pm 3.25$ \\
\hline & $\begin{array}{c}\text { Arteriyel } \\
\text { Yetmezlik }(n=5)\end{array}$ & 2 & 3 & & & $7.8 \pm 1.64$ & 3 & 2 & & & & $19.06 \pm 2.58$ & $6.96 \pm 1.47$ \\
\hline & $\begin{array}{c}\text { Venöz Yetmezlik } \\
(n=14)\end{array}$ & & 2 & 12 & & $14.43 \pm 3.2$ & & 2 & 7 & 5 & & $53.07 \pm 19.15$ & $8.8 \pm 6.27$ \\
\hline
\end{tabular}

PDUS: Penil Doppler ultrasonografi, IIEF: Erektil Fonksiyon Uluslararası İndeksi (International Index of Erectile Function), SHIM: Erkekler için Seksüel Sağlık Envanteri (Sexual Health Inventory for Men), PSV: Pik sistolik akım hızı, EDV: Diastol sonu hız.

Tablo-2. Doppler Tanısına Göre Oluşan 4 Bağımsız Grup (Normal, Arteriyel Yetmezlik İçin Sınırda, Arteriyel Yetmezlik ve Venöz Yetmezlik) Arasındaki Hasta Yaşı, Ereksiyon Düzeyi, IIEF-5 Skoru, SHIM, PSV ve EDV Değerleri Arasında Yapılan Karşılaştırma.

\begin{tabular}{|c|c|c|c|c|c|}
\hline & \multicolumn{4}{|c|}{ Penil Doppler Sınıflaması } & \multirow[b]{2}{*}{ P değeri } \\
\hline & Normal & $\begin{array}{c}\text { Arteriyel } \\
\text { yetmezlik için } \\
\text { borderline }\end{array}$ & $\begin{array}{l}\text { Arteriyel } \\
\text { Yetmezlik }\end{array}$ & $\begin{array}{l}\text { Venöz } \\
\text { Yetmezlik }\end{array}$ & \\
\hline Yaş & $55.67 \pm 9.42$ & $55.5 \pm 12.02$ & $62 \pm 7.18$ & $53.57 \pm 9.02$ & .269 \\
\hline $\begin{array}{l}\text { Ereksiyon } \\
\text { Düzeyi }\end{array}$ & $2.83 \pm 1.17$ & $1.5 \pm 0.71$ & $1.6 \pm 0.55$ & $2.86 \pm 0.36$ & .006 \\
\hline $\begin{array}{l}\text { IIEF-5 } \\
\text { Skoru }\end{array}$ & $18.5 \pm 2.07$ & $10 \pm 4.24$ & $7.8 \pm 1.64$ & $14.43 \pm 3.2$ & .001 \\
\hline SHIM & $4 \pm 0.63$ & $2 \pm 1.41$ & $1.4 \pm 0.55$ & $3.21 \pm 0.70$ & .001 \\
\hline PSV & $52.75 \pm 10.76$ & $28.6 \pm 1.98$ & $19.06 \pm 2.58$ & $53.07 \pm 19.15$ & .001 \\
\hline EDV & $-3.28 \pm 5.9$ & $6.3 \pm 3.25$ & $6.96 \pm 1.47$ & $8.8 \pm 6.27$ & .003 \\
\hline
\end{tabular}

IIEF: Erektil Fonksiyon Uluslararası İndeksi (International Index of Erectile Function), SHIM: Erkekler için Seksüel Sağlık Envanteri (Sexual Health Inventory for Men), PSV: Pik sistolik akım hızı, EDV: Diyastol sonu hız.

\section{Tartışma}

Hiperglisemi, dokular üzerinde çeşitli mekanizmalarla hasara neden olmaktadır. Hastalık ilerledikçe doku hasarı ve vasküler hasar ciddi komplikasyonlara yol açmaktadır. Nöropati, vasküler hastalık, nefropati ve retinopati gibi DM ile ilişkili kronik komplikasyonlar söz konusudur (19). ED da bu komplikasyonlar arasında özel bir ilgiyi hak etmektedir. Çalışmamızda izlenen yüksek orandaki (\%78) anormal Doppler sonucu, ED şikayeti bulunan DM hastalarında vasküler etiyolojinin önemini göstermektedir.

Erkeklerde en sık seksüel problem ED'dur. Çok uluslu, 27839 genel erkek popülasyonu üzerinde yapılan bir çalışmada ED prevalansı 20-30 yaş arasında \%8, 70-75 yaş düzeyinde \%37 olmak üzere genel ED prevalansı $\% 16$ olarak saptanmıştır (20). Diyabetik erkeklerde ise ED prevalansı yaş ile progresif olarak artmakta olup 2024 yaş aralığında \%6, 55-59 yaş aralığında \%52 düzeyinde bildirilmektedir (21). Ancak literatürde penil Doppler US tanısına göre verilmiş oranlara rastlamadık. Bizim çalışmamızda ED'lu diyabetik erkeklerin yaklaşık \%78'inde (21/27) anormal penil Doppler US bulguları elde edildi. Penil Doppler US tanısına göre hastaların \%22'si (6/27) normal, \%7'si (2/27) arteriyel yetmezlik için sınırda, \%19'u (5/27) arteriyel yetmezlik ve \%52'si (14/27) venöz yetmezlik olarak saptandı.

Birçok güncel çalışmada hipertansiyon, koroner arter hastalığı, kalp yetmezliği ve DM'nin içinde bulunduğu birçok komorbid durumun erektil disfonksiyon ile ilişkisi gösterilmiştir. Bununla beraber kardiyovasküler ve antihipertansif ilaçlar da ED gelişimine neden olabilmektedir. Tiazid tip diüretikler, aldosteron reseptör blokörleri, ß-adrenerjik reseptör blokörleri bu ilaçlardandır (22). Çalışma grubumuzdaki hastalarda hipertansiyon, hiperlipidemi, koroner ve periferik arter hastalıkları, kardiyak ritim bozukluğu ve son dönem böbrek yetmezliği görülen diğer problemlerdi. Bunların tedavilerinde kullanılan ilaçları da ED gelişimi için olası risk olarak ele alabiliriz.

Ayrıca bu komorbid hastalıklar, tedavi için kullanılan çeşitli ilaçlar ya da DM'de özellikle kronik süreçte gelişebilen diğer hasarların da ED gelişimine katkısı göz önüne alındığında ED gelişim sürecinin hastadan hastaya değişim gösteren bir durum olduğu kabul edilebilir. $\mathrm{Bu}$ nedenle Doppler tanılarının ve IIEF skorlarına göre ED seviyelerinin bizim çalışmamızda da 
olduğu gibi çeşitlilik göstermesi beklenen bir durum olacaktır.

Penil Doppler US, ED'nin değerlendirilmesinde değerli bir yöntemdir. Ancak penil kavernöz cisime papaverin enjeksiyonu nedeniyle gelişebilen priapizm komplikasyonu ve penil fibrozis gelişimi söz konusudur.

Yapılan bir retrospektif çalışmada, papaverinin intrakorporeal enjeksiyonu ile penil Doppler US incelemesi yapılmış 672 hastanın 18'inde (\%2.68) priapizm gelişmiş olduğu ve priapizm gelişen hastaların gelişmeyenlere kıyasla daha genç bir grubu temsil ettiği saptanmıştır. Yazarlar priapizm gelişim insidansının düşük olduğunu ve konservatif yaklaşımlarla başarı ile yönetildiğini belirtmişlerdir (23). Bazı çalışmalarda kavernöz arterde akım yokluğunun gelişmesi, Doppler sonrası ilk saatte PSV değerinin $66 \mathrm{~cm} / \mathrm{s}$ ya da daha fazla olması, beraberinde EDV'nin $0 \mathrm{~cm} / \mathrm{s}$ olması priapizm için prediktif olarak belirtilmiştir $(24,25)$. Priapizm gelişen hastaların Doppler değerleri incelendiğinde genel olarak anormal akım parametreleri (arteriyel ya da venöz yetmezlik) göstermedikleri değerlendirilebilir. Çalışmalarda belirtilmemiş olsa da bu durumda papaverin enjeksiyonu sonrası inceleme sürecinde gelişen ereksiyon sertlik derecelerinin de genel olarak tam olmuş olabileceği düşünülebilir. Çalışma grubumuzda ereksiyon sertlik seviyesi iki hastada tam düzeyde saptanmış olup bu hastalar Doppler bulgularına göre normal idi. Diğer hastalarda ereksiyon tam düzeyde değildi. Penil Doppler US işlemine bağlı olarak hiçbir hastada priapizm de dahil herhangi bir komplikasyon gelişmedi. Enjeksiyon sonrası penil Doppler US incelemesi yapılan hastalardan özellikle tam ereksiyon sertlik düzeyi gelişen, anormal Doppler bulgusu vermeyen hastalarda (arteriel ya da venöz yetmezlik) priapizm açısından daha dikkatli olunması gerektiğini düşünüyoruz.

Çalışmamızın limitasyonu olarak, mevcut hasta grubumuzun DM'li olsalar da diyabet tipi, eşlik eden hastalık çeşitliliği, glisemik kontrol durumu, kullanmakta oldukları tedaviler, hastalık süreleri gibi çok sayıda faktör açısından heterojen bir grubu temsil etmekte olduğunu belirtebiliriz. Ancak literatürdeki çoğu çalışmada olduğu gibi bu çeşitliliğin tamamen ekarte edilmesi mümkün görünmemektedir.

\section{Sonuç}

Diyabetik erkeklerde ED'nin ciddiyetinin diyabetin süresi, hasta yaşının ilerlemesi, kötü glisemik kontrol ve mikrovasküler komplikasyonların gelişimi ile arttığı bilinmektedir. Diyabetik erkeklerde ED, kompleks ve multifaktöriyel bir süreç olarak gözükmektedir. Bizim çalışmamızda literatüre ek olarak diyabetik erkeklerde ED'nin sebebi olarak vasküler kökenin ve özellikle venöz yetmezlik alt tipinin yüksek oranda görüldüğü saptandı. Çalışmamız mevcut bulgularıyla Türkçe literatüre sağladığı katkı açısından değerlidir, ancak konuyla ilgili daha net sonuca varılması açısından daha geniş vaka serili, çok merkezli çalışmalara ihtiyaç olduğu kanısındayız.

\section{Kaynaklar}

1. Williams SK, Melman A. Novel therapeutic targets for erectile dysfunction. Maturitas 2012;71(1):20-7.

2. Cohen SD. The challenge of erectile dysfunction management in the young man. Curr Urol Rep 2015;16(12):84.

3. Lewis RW. Epidemiology of erectile dysfunction. Urol Clin North Am 2001;28(2):209-16.

4. Binmoammar TA, Hassounah S, Alsaad S, Rawaf S, Majeed A. The impact of poor glycaemic control on the prevalence of erectile dysfunction in men with type 2 diabetes mellitus: A systematic review. JRSM Open 2016;7(3):1-10.

5. Penson DF, Latini DM, Lubeck DP, Wallace KL, Henning JM, Lue TF. Do impotent men with diabetes have more severe erectile dysfunction and worse quality of life than the general population of impotent patients? Results from the Exploratory Comprehensive Evaluation of Erectile Dysfunction (ExCEED) database. Diabetes Care 2003;26(4):1093-9.

6. Goldstein I, Lue TF, Padma-Nathan H, Rosen RC, Steers WD, Wicker PA. Oral sildenafil in the treatment of erectile dysfunction. Sildenafil Study Group. N Engl J Med 1998;338(20):1397-404.

7. Mäkimattila S, Yki-Järvinen H. Endothelial dysfunction in human diabetes. Curr Diab Rep 2002;2(1):26-36.

8. Chitaley K. Type 1 and type 2 diabetic-erectile dysfunction: Same diagnosis (ICD-9), different disease? J Sex Med 2009;6(Suppl 3):262-8.

9. Kirilmaz U, Guzel O, Aslan Y, Balci M, Tuncel A, Atan A. The effect of lifestyle modification and glycemic control on the efficiency of sildenafil citrate in patients with erectile dysfunction due to type-2 diabetes mellitus. Aging Male 2015;18(4):244-8.

10. Gupta N, Herati A, Gilbert BR. Penile Doppler ultrasound predicting cardiovascular disease in men with erectile dysfunction. Curr Urol Rep 2015;16(3):16.

11. Lue TF, Hricak H, Marich KW, Tanagho EA. Vasculogenic impotence evaluated by high-resolution ultrasonography and pulsed Doppler spectrum analysis. Radiology 1985;155(3):777-81.

12. Rosen RC, Riley A, Wagner G, Osterloh IH, Kirkpatrick J, Mishra A. The international index of erectile function (IIEF): A multidimensional scale for assessment of erectile dysfunction. Urology 1997;49(6):822-30.

13. Rosen RC, Cappalleri JC, Smith MD, Lipsky J, Pena BM. Development and evaluation of an abridged, 5 -item version of the International Index of Erectile Function (IIEF-5) as a diagnostic tool for erectile dysfunction. Int J Impot Res 1999;11(6):319-26.

14. Dargis L, Trudel G, Cadieux J, Villeneuve L, Préville M, Boyer R. Validation of the International Index of Erectile Function (IIEF) and presentation of norms in older men. Sexologies 2013;22(1):e20-e26.

15. Rosen RC, Cappalleri JC, Gendrano N 3rd. The international index of erectile function (IIEF): A state-of-the-science review. Int $J$ Impot Res 2002;14(4):226-44. 
16. Fitzgerald SW, Erickson SJ, Foley WD, Lipchik EO, Lawson TL. Color Doppler sonography in the evaluation of erectile dysfunction. Radiographics 1992;12(1):3-17.

17. Pereira JA, Bilhim T, Rio Tinto H, Fernandes L, Martins Pisco J, Goyri-O'Neill J. Radiologic anatomy of arteriogenic erectile dysfunction: A systematized approach. Acta Med Port 2013;26(3):219-25.

18. Aslan Y, Tuncel A, Aydin O, Balci M, Karabulut E, Atan A. The association between Erection Hardness Grading Scale and International Index of Erectile Function in men with erectile dysfunction treated with sildenafil citrate. Urol Int 2011;86(4):434-8.

19. Defeudis G, Gianfrilli D, Di Emidio C, et al. Erectile dysfunction and its management in patients with diabetes mellitus. Rev Endocr Metab Disord 2015;16(3):213-31.

20. Rosen RC, Fisher WA, Eardley I, Niederberger C, Nadel A, Sand M. The multinational Men's Attitudes to Life Events and Sexuality (MALES) study: I. Prevalence of erectile dysfunction and related health concerns in the general population. Curr Med Res Opin 2004;20(5):607-17.

21. McCulloch DK, Campbell IW, Wu FC, Prescott RJ, Clarke BF. The prevalence of diabetic impotence. Diabetologia 1980;18(4):279-83.

22. Chrysant SG. Antihypertensive therapy causes erectile dysfunction. Curr Opin Cardiol 2015;30(4):383-90.

23. Kilic M, Serefoglu EC, Ozdemir AT, Balbay MD. The actual incidence of papaverine-induced priapism in patients with erectile dysfunction following penile colour Doppler ultrasonography. Andrologia 2010;42(1):1-4.

24. Secil M, Arslan D, Goktay AY, Esen AA, Dicle O, Pirnar T. The prediction of papaverine induced priapism by color Doppler sonography. J Urol 2001;165(2):416-8.

25. Metawea B, El-Nashar AR, Gad-Allah A, Abdul-Wahab M, Shamloul R. Intracavernous papaverine/phentolamine-induced priapism can be accurately predicted with color Doppler ultrasonography. Urology 2005;66(4):858-60. 